\title{
ĐẶC ĐIỂM VÀ ẢNH HƯởNG CỦA GIỚI TÍNH ĐẾN KẾT QUẢ ĐIỀU TR! BỎNG Ở NGƯờI CAO TUỔI
}

\author{
Ngô Minh Đức, Nguyễn Như Lâm \\ Bệnh viện Bỏng Quốc gia Lê Hữu Trác
}

\section{TÓM TẮT}

Mục tiêu: Xác định đặc điểm và mối liên quan giữa giới tính với kết quả điều trị bệnh nhân bỏng ở người cao tuổi.

Đối tượng và phương pháp nghiên cứu: Nghiên cứu hồi cứu trên 629 bệnh nhân bỏng người cao tuổi ( $\geq 65$ tuổi) điều trị nội trú tại Bệnh viện Bỏng Quốc gia trong giai đoạn từ năm 2015 - 2019. Các chỉ tiêu về nhân khẩu học, đặc điểm tổn thương bỏng, kết quả diều trị được so sánh giữa hai nhóm bệnh nhân nam và nữ.

Kết quả: Tỷ lệ bệnh nhân nam và nữ là 51,03\% và 48,97\%. Bệnh nhân nữ có tuổi cao hơn (75 tuổi so với 72 tuổi; $p<0,05)$, tác nhân gây bỏng chủ yếu là nhiệt ướt (56,49\%), trong khi ở nam giới chủ yếu là do nhiệt khô $(57,94 \% ; p<0,01)$. So với nhóm bệnh nhân nữ, nhóm bệnh nhân nam có tỷ lệ bỏng sâu cao hơn đáng kể (66,67\% so với $54,87 \% ; p<0,05)$.

Diện tích bỏng chung, diện tích bỏng sâu, tỷ lệ bỏng hô hấp và số lần phẫu thuật không khác nhau đáng kể giữa hai giới $(p>0,05)$. Chi phí điều trị trung bình cho $1 \%$ diện tích bỏng sâu ở nhóm bệnh nhân nam cao hơn đáng kể so với nhóm bệnh nhân nữ ( $p$ < 0,05). Tỷ lệ tử vong ở nam giới cao hơn (13,08\% so với 9,74\%), thời điểm tử vong sau bỏng sớm hơn (9,5 so với 11,5 ngày) nhưng sự khác biệt chưa có ý nghĩa thống kê.

Kết luận: Ở người cao tuổi, tác nhân bỏng chủ yếu là nhiệt ướt ở nữ giới và nhiệt khô ở nam giới. Bệnh nhân nam giới có tỷ lệ bị bỏng sâu và chi phí điều trị bỏng sâu cao hơn đáng kể. Tuy nhiên kết quả điều trị không có sự khác biệt giữa hai giới.

Tì̛ khóa: Bỏng, người cao tuổi, giới tính, kết quả điều trị

\begin{abstract}
Objective: The aim of this study was to investigate characteristics and relationships of gender with outcomes of elderly burn patients.

Patients and method: A retrospective study was conducted on 629 elderly burn patients (65 $\geq$ years old) admitted to the National Burn Hospital over a period from 2015 to 2019. Demographic data, burn features and outcomes of male and female groups were compared.
\end{abstract}

${ }^{1}$ Chịu trách nhiệm: Nguyễn Như Lâm, Bệnh viện Bỏng Quốc gia Lê Hữu Trác

Email: lamnguyenau@yahoo.com

Ngày nhận bài: 11/7/2021; Ngày phản biện: 09/8/2021; Ngày duyệt bài: 30/8/2021 
Results: Men accounted for $51.03 \%$ and women accounted for $48.97 \%$ of the total patients. Years old of female patients were older than men (75 years old vs 72 years; $p<$ $0.05)$ with the main causal agent was wet heat (56.49\%) while in men, it was due to dry heat (57.94\%; $p<0.01)$.

The incidence of deep burn injury was remarkably higher in male patients $(66.67 \%$ vs. $54.87 \% ; p<0.05)$. Burn extent, full-thickness burn area, the incidence of inhalation injury and the number of surgical interventions was insignificant differences across genders ( $p>$ 0.05). The average treatment cost for $1 \%$ of deep burn area was significantly higher in male patients $(p<0.05)$. The mortality rate of male patients was higher $(13.08 \%$ compared with 9.74\%), the time point of death after the burn was earlier (9.5 vs 11.5 days) but the difference was not statistically significant.

Conclusion: Amongst elderly burn patients, the common causal agent was humid heat for females and dry heat for men. Male patients appeared to suffer a higher rate and treatment cost for deep burn injury. However, outcomes were not significantly different across genders.

Keywords: Burn, elderly, gender, outcomes

\section{1. ĐĂT VẤN ĐỀ}

Theo tổ chức $\mathrm{Y}$ tế Thế giới, từ 65 tuổi trở lên được coi là người cao tuổi. Hiện nay trên thế giới, người cao tuổi chiếm khoảng 30\% tổng số bệnh nhân nội trú tại các bệnh viện. Trong nhóm người cao tuổi, có những sự khác biệt về tâm sinh lý, thể chất giữa nam và nữ. Nhiều công trình nghiên cứu đã đề cập đến sự khác biệt về kết quả điều trị của bệnh nhân theo giới tính trong đó có người cao tuổi. Theo đó, tỷ lệ tử vong của nữ giới thấp hơn đáng kể so với nam giới khi mắc các bệnh lý mạn tính, xuất huyết, nhiễm khuẩn. Tuy nhiên, trên bệnh nhân chấn thương (bao gồm cả bệnh nhân bỏng) vẫn còn kết quả khác nhau về ảnh hưởng của giới tính đến kết quả điều trị [1].

Mục đích của nghiên cứu này là xác định ảnh hưởng của giới tính đối với đặc điểm và kết quả điều trị bệnh nhân bỏng là người cao tuổi điều trị tại Bệnh viện Bỏng Quốc gia giai đoạn năm 2015 - 2019.

\section{2. ĐỐI TƯỚNG VÀ PHƯỞNG PHÁP NGHIÊN CỨU}

Nghiên cứu hồi cứu trên 629 bệnh nhân bỏng cao tuổi ( $\geq 65$ tuổi) điều trị nội trúở Bệnh viện Bỏng Quốc gia từ ngày $1 / 1 / 2015$ đến ngày $31 / 12 / 2019$. Các chỉ tiêu thu thập bao gồm tuổi, giới, nơi cư trú (nông thôn hay thành thị), đối tượng (có bảo hiểm y tế hay không), thời gian nhập viện sau bỏng (trước hay sau 24h), tác nhân bỏng, mùa bị bỏng trong năm, vị trí bỏng, diện tích bỏng chung, diện tích bỏng sâu, bỏng hô hấp, thời gian nằm viện, số lần phẫu thuật, chi phí điều trị cho $1 \%$ diện tích bỏng, kết quả điều trị (tử vong hay được cứu sống) và thời điểm tử vong sau bỏng.

Số liệu được tổng hợp, phân tích và so sánh giữa hai nhóm bệnh nhân nam và nữ trên phần mềm Stata 14.0, giá trị $p<0,05$ được coi là có ý nghĩa thống kê. 


\section{KẾT QUẢ NGHIÊN CỨU}

Bảng 1. Đặc điểm bệnh nhân nghiên cứu

\begin{tabular}{|c|c|c|c|c|}
\hline Đặc điểm & Nhóm & $\begin{array}{c}\text { Nam } \\
(n=321)\end{array}$ & $\begin{array}{c}\text { Nũ̃ } \\
(n=308)\end{array}$ & $\mathbf{p}$ \\
\hline \multicolumn{2}{|c|}{ Tuổi } & $72(67-79)$ & $75(68-82)$ & 0,03 \\
\hline \multirow{4}{*}{ Mùa bị bỏng } & Xuân & $78(24,3)$ & $96(31,7)$ & \multirow{4}{*}{0,19} \\
\hline & $\mathrm{Hạ}$ & $84(26,17)$ & $66(21,43)$ & \\
\hline & Thu & $77(24,68)$ & $76(23,99)$ & \\
\hline & Đông & $82(25,55)$ & $70(22,73)$ & \\
\hline \multirow{4}{*}{ Tác nhân } & Nhiệt ướt & $85(26,48)$ & $174(56,49)$ & \multirow{4}{*}{0,001} \\
\hline & Nhiệt khô & $186(57,94)$ & $118(38,31)$ & \\
\hline & Điện & $49(15,26)$ & $10(3,25)$ & \\
\hline & Hóa chất & $01(0,31)$ & $06(1,95)$ & \\
\hline \multirow{2}{*}{ Nơi cư trú } & Nông thôn & $164(53,25)$ & $186(57,94)$ & \multirow{2}{*}{0,23} \\
\hline & Thành thị & $144(46,75)$ & $135(42,06)$ & \\
\hline \multicolumn{2}{|c|}{ Bảo hiểm y tế } & $301(96,26)$ & $275(89,29)$ & 0,001 \\
\hline \multirow{2}{*}{$\begin{array}{l}\text { Thời điểm vào viện } \\
\text { sau bỏng }\end{array}$} & $<24 h$ & $62(20,13)$ & $68(21,18)$ & \multirow{2}{*}{0,74} \\
\hline & $\geq 24 \mathrm{~h}$ & $246(79,87)$ & $253(78,82)$ & \\
\hline Bệnh kết hợp & & $85(27,6)$ & $103(33,02)$ & 0,13 \\
\hline
\end{tabular}

Trong tổng số 629 bệnh nhân cao tuổi yếu là nhiệt khô $(57,94 \%)$, sự khác biệt có điều trị tại Bệnh viện Bỏng Quốc gia trong ý nghĩa thống kê với $p=0,001$. Tỷ lệ bệnh gai đoạn 2015 - 2019, tỷ lệ nam nữ gần nhân nam có bảo hiểm y tế cao hơn tương đương nhau (nam giới 51,03\%, nữ $\quad(96,26 \%$ so với $89,29 \% ; p=0,01)$. Không 48,97\%). Tuổi của bệnh nhân nữ cao hơn có sự khác biệt giữa hai giới về đặc điểm nam (75 tuổi so với 72 tuổi; $p<0,05)$. Tác nơi cư trú, mùa bị bỏng trong năm, thời nhân gây bỏng chủ yếu ở nữ giới là nhiệt điểm nhập viện sau bỏng cũng như tỷ lệ bị ướt $(56,49 \%)$ trong khi đó ở nam giới chủ bệnh kết hợp $(p>0,05)$.

Bảng 2. Đặc điểm tổn thương bỏng

\begin{tabular}{|l|c|c|c|}
\hline \multicolumn{1}{|c|}{ Đặc điểm } & $\begin{array}{c}\text { Nam } \\
(\mathbf{n = 3 2 1 )}\end{array}$ & $\begin{array}{c}\mathbf{N u} \\
(\mathbf{n}=\mathbf{3 0 8})\end{array}$ & $\mathbf{p}$ \\
\hline Diện tích bỏng, \%DTCT & $5(1-16)$ & $4(2-10,5)$ & 0,14 \\
\hline Bỏng sâu, n (\%) & $214(66,67)$ & $169(54,87)$ & 0,002 \\
\hline Diện tích bỏng sâu, \%DTCT & $3(1-9)$ & $3(1-8)$ & 0,47 \\
\hline Bỏng hô hấp, n (\%) & $11(3,57)$ & $13(4,05)$ & 0,75 \\
\hline Bỏng mặt, $n(\%)$ & $65(20,25)$ & $60(19,48)$ & 0,08 \\
\hline
\end{tabular}




\begin{tabular}{|l|c|c|c|}
\hline \multicolumn{1}{|c|}{ Đặc điểm } & $\begin{array}{c}\text { Nam } \\
(\mathbf{n = 3 2 1 )}\end{array}$ & $\begin{array}{c}\text { Nữ } \\
(\mathbf{n}=\mathbf{3 0 8})\end{array}$ & $\mathbf{p}$ \\
\hline Bỏng vùng đầu, $\mathrm{n}(\%)$ & $07(2,18)$ & $13(4,22)$ & 0,14 \\
\hline Bỏng vùng cổ, $\mathrm{n}(\%)$ & $45(14,02)$ & $36(11,69)$ & 0,38 \\
\hline Bỏng thân trước, $\mathrm{n}(\%)$ & $109(33,96)$ & $104(33,72)$ & 0,96 \\
\hline Bỏng thân sau, $\mathrm{n}(\%)$ & $113(35,2)$ & $95(30,84)$ & 0,24 \\
\hline Bỏng chi trên, $\mathrm{n}(\%)$ & $193(60,12)$ & $149(48,38)$ & 0,003 \\
\hline Bỏng chi dưới, $\mathrm{n}(\%)$ & $227(70,72)$ & $216(70,13)$ & 0,87 \\
\hline Bỏng sinh dục, $\mathrm{n}(\%)$ & $15(4,67)$ & $12(3,9)$ & 0,63 \\
\hline Chấn thương kết hợp & $04(1,3)$ & $03(0,93)$ & 0,66 \\
\hline
\end{tabular}

DTCT: Diện tích cơ thể

Diện tích bỏng chung và diện tích bỏng sâu của hai giới khác nhau không có ý nghĩa thống kê $(p>0,05)$, tuy nhiên tỷ lệ bệnh nhân bỏng sâu ở nhóm bệnh nhân nam giới cao hơn đáng kể $(66,67 \%$ so với
54,87\%; $p<0,05)$. Bệnh nhân nam giới còn có tỷ lệ bỏng ở chi trên cao hơn đáng kể $(60,12 \%$ so với $48,38 \% ; p=0,003)$. Tỷ lệ bỏng hô hấp và chấn thương kết hợp tương đương giữa hai nhóm $(p>0,05)$.

Bảng 3. Diễn biến và kết quả điều trị

\begin{tabular}{|l|c|c|c|}
\hline \multicolumn{1}{|c|}{ Đặc điểm } & $\begin{array}{c}\text { Nam } \\
(\mathbf{n = 3 2 1 )}\end{array}$ & $\begin{array}{c}\mathbf{N} \text { Nư } \\
(\mathbf{n}=\mathbf{3 0 8})\end{array}$ & $\mathbf{p}$ \\
\hline Thời gian điều trị, ngày & $13(7-22)$ & $11(7-19)$ & 0,12 \\
\hline Số lần phẫu thuật, lần & $2(1-3)$ & $2(1-2)$ & 0,76 \\
\hline Chi phí điều trị/1\%DTCT bỏng nông ${ }^{*}$, triệu VNĐ & $1,24(0,81-2,94)$ & $1,6(0,7-3,4)$ & 0,37 \\
\hline Chi phí điều trị/1\%DTCT bỏng sâu**, triệu VNĐ & $9,2(4,2-20.1)$ & $6,9(4,0-12,7)$ & 0,031 \\
\hline Tử vong, n(\%) & $42(13,08)$ & $30(9,74)$ & 0,18 \\
\hline Thời điểm tử vong sau bỏng, ngày & $9,5(2-13)$ & $11,5(2-19)$ & 0,14 \\
\hline
\end{tabular}

DTBS: Diện tích bỏng sâu.

*: Chỉ tính bệnh nhân bỏng nông (107 bệnh nhân nam và 139 bệnh nhân nữ);

**: Chỉ tính bệnh nhân bỏng sâu (214 bệnh nhân nam và 169 bệnh nhân nữ)

Thời gian điều trị, số lần phẫu thuật khác nhau không có ý nghĩa thống kê giữa hai giới $(p>0,05)$. Chi phí điều trị cho $1 \%$ diện tích bỏng của bệnh nhân bỏng nông tương đương giữa hai nhóm (1,24 triệu đồng so với 1,6 triệu đồng; $p>0,05$ ) nhưng chi phí điều trị cho $1 \%$ diện tích bỏng sâu cao hơn đáng kể ở nhóm bệnh nhân nam giới (9,2 triệu đồng so với 6,9 triệu đồng; $p=$ 0,031). Tỷ lệ tử vong ở nhóm bệnh nhân nam cao hơn so với nhóm bệnh nhân nữ tuy nhiên, khác biệt chưa có ý nghĩa thống kê $(13,08 \%$ so với $9,74 \% ; p=0,18)$. Thời điểm tử vong sau bỏng ở nam giới sớm hơn (9,5 so với 11,5 ngày) nhưng khác biệt cũng không có ý nghĩa thống kê với p > 0,05. 


\section{BÀN LUẬN}

Cùng với sự phát triển của kinh tế và xã hội, tuổi thọ của người dân ngày càng được nâng cao. Tỷ lệ dân số già gia tăng dẫn tới thay đổi cơ cấu bệnh tật, chấn thương trong đó có tai nạn bỏng. Các nghiên cứu cho thấy, ở hầu hết các quốc gia tỷ lệ phụ nữ cao tuổi luôn cao hơn nam giới. Ngoài ra, phụ nữ cũng có nhiều người sống phần sau của cuộc đời mà không có bạn đời hơn nam giới. Một số vấn đề sức khỏe đối với nam giới cao tuổi là thiểu năng sinh dục, rối loạn cương dương và phì đại tuyến tiền liệt, còn đối với nữ giới cao tuổi là rối loạn sau mãn kinh, tiểu không kiểm soát, ung thư vú và phổi. Tuy nhiên, cũng có những vấn đề sức khoẻ chung ở cả hai giới bao gồm bệnh mạn tính, suy dinh dưỡng, tai nạn và rối loạn chức năng nhận thức. Trong gia đình người phụ nữ vẫn đóng vai trò nội trợ là chính và một bộ phận không nhỏ nam giới cao tuổi vẫn tham gia lao động sản xuất, sửa chữa trong nhà do vậy nữ giới thường bị bỏng do nhiệt ướt, trong khi nam giới thường bị bỏng do nhiệt khô và điện 1 . Kết quả nghiên cứu của chúng tôi phù hợp với nhận định này. Nghiên cứu của Perkins $M$ và cộng sự (2020) cũng cho kết quả tương tự [2].

Về tỷ lệ, độ tuổi và mức độ bỏng theo giới, các nghiên cứu cho các kết quả khác nhau. Mabrouk A và cộng sự (2003) thông báo, trong số người cao tuổi bị bỏng, tuổi của nữ cao hơn nam (68 so với 63,5 tuổi) [3].

Gregg D và cộng sự (2018) thông báo tỷ lệ bệnh nhân nữ bị bỏng cao hơn nam giới ( $58 \%$ so với $42 \%$ ) ở nhóm bệnh nhân trên 70 tuổi [4].
Trong khi đó, nghiên cứu của Chang EJ và cộng sự (2005) cho thấy so với nam giới cao tuổi, phụ nữ cao tuổi chiếm tỷ lệ thấp hơn (33\% so với $67 \%)$, diện tích bỏng it hơn (12\% so với $17,2 \%$ DTCT) và diện tích bỏng sâu cũng ít hơn $(3,6 \%$ so với 9,7\% DTCT; $p<0,05$ ) [5].

Blom L và cộng sự (2016) cũng thông báo tỷ lệ bỏng ở người có tuổi (> 55 tuổi) của nam cao hơn nữ $(3,6 \%$ so với $1,9 \%$ tổng số bệnh nhân bỏng điều trị tại trung tâm bỏng) [6].

Trong nghiên cứu của chúng tôi, tỷ lệ nam nữ gần tương đương nhau, với độ tuổi cao hơn ở nữ giới, đồng thời diện tích bỏng tương đương hai nhóm chỉ có tỷ lệ bỏng sâu cao hơn ở nam giới. Sự khác nhau về kết quả giữa các nghiên cứu có thể do cỡ mẫu nghiên cứu, độ tuổi nghiên cứu. Một số nghiên cứu xác định người cao tuổi là từ 60 tuổi trở lên, một số khác từ 65 tuổi, hoặc 70 tuổi trở lên. Trong nghiên cứu này, chúng tôi xác định theo định nghĩa của tổ chức $\mathrm{y}$ tế thế giới về người cao tuổi là từ 65 tuổi trở lên.

Trên bệnh nhân bỏng người lớn, đa phần các tác giả thông báo tỷ lệ tử vong ở bệnh nhân nữ cao hơn bệnh nhân nam ở cùng độ tuổi. Ví dụ như nghiên cứu của McGwin GJr và cộng sự (2002) chỉ ra rằng tỷ lệ tử vong ở nữ cao hơn gấp đôi so với nam giới $(O R=2,3)[7]$.

Đối với nhóm bệnh nhân cao tuổi, nghiên cứu của O'Keefe GE và cộng sự (2001) cho thấy, giới tính không ảnh hưởng đáng kể đến tỷ lệ tử vong [8]. Các nghiên cứu của Chang $\mathrm{EJ}$ và cộng sự, của Kobayashi $K$ và cộng sự và của chúng tôi cũng cho kết quả tương tự $[5,9]$. Ngoài ra, kết quả nghiên cứu của chúng tôi cũng cho thấy không có sự khác biệt về tỷ lệ và thời 
điểm tử vong giữa nam và nữ cao tuổi. Kết quả này cũng phù hợp với thông báo của Penkins M và cộng sự năm 2020 [2].

\section{KẾT LUẬN}

Ở người cao tuổi, tỷ lệ bỏng tương đương giữa hai giới. Bệnh nhân nữ bị bỏng chủ yếu do sức nhiệt ướt (56,49\%), trong khi ở nam giới chủ yếu là nhiệt khô $(57,94 \%)$. So với nhóm bệnh nhân nữ, bệnh nhân nam có tuổi thấp hơn (72 so với 75 tuổi; $p<0,05$ ), tỷ lệ bỏng sâu và chi phí điều trị bỏng sâu cao hơn đáng kể $(p<0,05)$. Tuy nhiên, tỷ lệ tử vong và thời điểm tử vong không khác nhau đáng kể giữa hai giới tính.

\section{TÀI LIẸU THAM KHẢO}

1. Dhar HL. Gender, aging, health and society. J Assoc Physicians India. 2001; 49: 1012-20.

2. Perkins $M$, Abesamis GM, Cleland $H$, Gabbe BJ, Tracy L M. Association between gender and outcomes of acute burns patients. ANZ Journal of Surgery. 2020; 91(1-2): 83-88.

3. Mabrouk A, Maher A, Nasser S. An epidemiologic study of elderly burn patients in Ain Shams University Burn Unit, Cairo, Egypt. Burns. 2003; 29(7): 687-690.
4. Gregg D, Patil S, Singh K, Marano MA, Lee R, et al. Clinical outcomes after burns in elderly patients over 70 years: A 17-year retrospective analysis. Burns. 2018; 44(1): 65-69.

5. Chang EJ, Edelman LS, Morris SE, Saffle JR. Gender influences on burn outcomes in the elderly. Burns. 2005; 31(1): 31-35.

6. Blom L, Klingberg A, Laflamme $L$, Wallis $L$, Hasselberg M. Gender differences in burns: A study from emergency centers in the Western Cape, South Africa. Burns. 2016; 42(7): 16001608.

7. McGwin GJr, George RL, Cross JM, Reiff DA. Gender differences in mortality following burn injury. Shock. 2002; 18(4):311-315.

8. O'Keefe GE, Hunt, JL, Purdue GF. An evaluation of risk factors for mortality after burn trauma and the identification of genderdependent differences in outcomes11No competing interests declared. Journal of the American College of Surgeons. 2001; 192(2): 153-160.

9. Kobayashi K, Ikeda H, Higuchi R, Nozaki M, et al. Epidemiological and outcome characteristics of major burns in Tokyo. Burns. 2005; 31 Suppl 1: S3-S11. 